\title{
Factors affecting extraction of adsorbed wine volatile compounds and wood extractives from used oak wood
}

\author{
Eduardo Coelho*, José A. Teixeira, Lucília Domingues, Teresa Tavares, José M. Oliveira \\ CEB - Centre of Biological Engineering, University of Minho, Campus Gualtar, 4710-057 Braga, Portugal
}

\section{A R T I C L E I N F O}

\section{Keywords:}

Wood sorption

Hydrophobic adsorption

Wine volatiles

Wood extractives

Wood ageing

\begin{abstract}
A B S T R A C T
During ageing, wood adsorbs volatile compounds from beverages. However, chemical interactions involved in sorption still remain unclear, as well as wood capacity to transfer such compounds to subsequent matrices when reused. Therefore, extractions were conducted from used wood manipulating variables such as ethanol concentration, contact temperature and $\mathrm{pH}$, in order to determine their effect in the interaction and consequent recovery of wine volatiles from wood. Mathematical models were outlined, which demonstrated an exclusive effect of ethanol concentration on the extraction of wine volatiles adsorbed in wood, more prominent for compounds of higher hydrophobicity. Thus adsorption of wine volatiles was shown to be based on hydrophobic interactions. Recovery of wood extractives was also modeled, confirming the known positive effect of ethanol and temperature on the overall extraction of characteristic wood compounds. When reused, wood transferred wine compounds to hydroalcoholic matrices, demonstrating its impact and potential as a vector for aroma transference.
\end{abstract}

\section{Introduction}

Generally, spirits and wines are aged by contact with oak wood. During contact, wood compounds are extracted into the beverage and several other reactions and transformations occur which enhance the beverage sensory properties. Several works have identified the main wood extractives, namely phenolic compounds (Zhang, Cai, Duan, Reeves, \& He, 2015), furanic compounds (Garcia, Soares, Dias, Freitas, \& Cabrita, 2012), lactones and aldehydes (De Rosso, Cancian, Panighel, Dalla Vedova, \& Flamini, 2009; Mosedale \& Puech, 1998) which determine the beverage sensory quality. Depending on the beverage to be aged, the casks employed can be new or reused from ageing other beverages. Bourbon is aged in new unused cooperage wood (Gonzalez, 2014; Lyons, 2014), as well as brandy which undergoes a short first contact with unused wood and a second one in used barrels for a longer ageing period (Caldeira, Mateus, \& Belchior, 2006). Whisky and beer are generally aged in previously used casks from the production of other beverages, generally from bourbon or fortified wine (Quinn, 2014; Roullier-Gall et al., 2018; Spitaels et al., 2014). Wine can be aged either in new or used casks (Cerdán \& Ancín-Azpilicueta, 2006). The content of extractives in wood depends highly on the species used (De Rosso et al., 2009), geographic origin, coarseness of wood grain (Jordão, Ricardo-Da-Silva, \& Laureano, 2007) drying/seasoning methods, and the toasting methods used in cooperage manufacture
(Chira \& Teissedre, 2014; Fernández de Simón, Cadahía, del Álamo, \& Nevares, 2010; González-Centeno, Chira, \& Teissedre, 2016). During successive reutilizations, wood will lose richness in extractible compounds and become depleted, because their content in wood is finite (Gómez-Plaza, Pérez-Prieto, Fernández-Fernández, \& López-Roca, 2004; Wilkinson, Li, Grbin, \& Warren, 2013). Besides becoming depleted of extractives, wood also becomes enriched with the beverage composition. Several different families of compounds were found to adsorb onto wood during contact, namely monomeric volatile phenols (Barrera-García, Gougeon, Voilley, \& Chassagne, 2006) polyphenols, namely monomeric anthocyanins, (+)-catechin, (-)-epicatechin, gallic acid, and trans-resveratrol (Barrera-García et al., 2007) and wine volatile compounds, namely terpenes, alcohols, esters, aldehydes, norisoprenoids and acids (Coelho, Domingues, Teixeira, Oliveira, \& Tavares, 2019; Ramirez et al., 2001). Several mechanisms were proposed for interaction of wine compounds with wood. Ramirez and collaborators proposed that sorption of wine volatiles relied on polar and acid base characteristics of wood, stating that solubility and hydrophobicity of compounds was not related with the phenomenon (Ramirez et al., 2001). Later on, in a study focusing interaction of wine constituents on wood sorption of wine aromas, Ramirez and collaborators hypothesized that hydrophobicity could indeed be involved in wood sorption, for a small pool of wine volatile compounds in a synthetic matrix (Ramirez-Ramirez, Chassagne, Feuillat, Voilley, \&

\footnotetext{
* Corresponding author.

E-mail address: e.coelho@ceb.uminho.pt (E. Coelho).
} 
Charpentier, 2004). This hypothesis was later confirmed in the study of sorption monomeric volatile phenols by wood, where Barrera-Garcia and collaborators demonstrated that the main wood macromolecules, namely cellulose, hemicellulose and lignin were involved in the interactions established (Barrera-García, Gougeon, Karbowiak, Voilley, \& Chassagne, 2008). Sorption of these compounds was found to be dependent both on wood macromolecules and on sorbate chemical structure, with lignin demonstrating selective adsorption, involving mainly hydrophobic interactions (Barrera-García et al., 2008). In recent works, focusing also wood sorption of wine compounds, the importance of mass transference was demonstrated in the uptake of wine by wood, accompanied by the identification of the wine volatiles adsorbed (Coelho et al., 2019). However, the adsorption mechanism of wine volatile compounds to wood remained to be confirmed, on the basis of the previously mentioned works. Thus the first hypothesis proposed in this work is that wine volatiles interact with oak wood due to hydrophobic interactions. Furthermore, despite the knowledge available on the sorption of wine volatiles and depletion of typical wood extractives, little is known about extraction of these compounds from used wood when applying it in successive ageing processes. Hence, the second proposed hypothesis is that wood is a vector for transferring volatile compounds between beverages, such as wine, beer or spirits, when reused consecutively.

To test both proposed hypotheses, this work explores the extraction of wine volatile compounds from used wood by studying the effect of variables capable of disrupting binding between sorbent and sorbate.

\section{Materials and methods}

\subsection{Chemicals and materials}

Determination of GC-MS spectra and retention indexes was performed with the following compounds with the corresponding purity. From Fluka, 3-methyl-1-butanol ( $\geq 99.8 \%$ ), 2-phenylethanol ( $\geq 99 \%$ ), furfural (99\%) and vanillin ( $\geq 98 \%$ ). From Aldrich, isoamyl acetate ( $\geq 99 \%$ ), ethyl hexanoate ( $\geq 99 \%$ ), ethyl lactate (98\%), ethyl octanoate ( $\geq 99 \%$ ), diethyl succinate (99\%), diethyl malate ( $\geq 97 \%$ ), octanoic acid ( $\geq 99.5 \%)$, 5-methylfurfural (99\%), 4-methylguaiacol ( $\geq 98 \%$ ), guaiacol (98\%), 2,6-dimethoxyphenol (99\%), eugenol (99\%), cis/transoak lactone ( $\geq 98 \%$ ), acetovanillone (98\%) and syringaldehyde (98\%). From Acros Organics, 5-hydroxymethylfurfural (98\%) and, from Alfa Aesar, 4-ethylguaiacol (98\%). Only sinapaldehyde was identified using the retention index and the NIST08 mass spectral library.

Fortified wine was chosen for the prior contact with wood considering that is the type of barrel reused by most industries and that it poses a lower risk for spreading undesirable microbial spoilage traits due to its higher ethanol content. Unaged fortified wine utilized for the preparation of the used oak woods was kindly provided by Quinta do Portal S.A., with an ethanol content, by volume, of $20.9 \% \pm 0.3 \%$. Before contact with wood, unaged fortified wine didn't have any content in wood extractives, being its composition reported in Coelho et al. (2019). Toasted French oak (Q. robur) $950 \times 50 \times 18 \mathrm{~mm}^{3}$ and toasted American oak (Q. alba) $950 \times 50 \times 6 \mathrm{~mm}^{3}$ staves, from the Oenostave ${ }^{\circledR}$ series (kindly provided by Seguin Moreau, France), were used in this work. Staves of both varieties were supplied with the $\mathrm{M}+$ toasting level, that in cooperage corresponds to a $68 \mathrm{~min}$ toast at $62{ }^{\circ} \mathrm{C} \pm 3{ }^{\circ} \mathrm{C}$ without water addition (Chira \& Teissedre, 2014). Toasted American and French oak without any prior usage did not have any content in wine volatile compounds, which where adsorbed during contact with fortified wine as reported in Coelho et al. (2019), where compositions of unused and used woods are presented.

\subsection{Preparation of used wood samples}

The designation of used wood in this work refers to cooperage wood after contact with fortified wine, characterized by presence of adsorbed wine volatile compounds and a lower content in wood extractives, in opposition with the characteristics of unused cooperage wood as demonstrated in Coelho et al. (2019). For reproducibility and control purposes, used wood samples were prepared in the laboratory in accordance with the procedures described in Coelho et al. (2019). Wood staves were cut into cubes of $3 \mathrm{~mm}$ side with a vertical saw in the transversal direction and with a blade in the longitudinal direction, using a pachymeter for confirmation of individual chip dimensions. Chips were then immersed in the fortified wine, at a ratio (wood/wine) of $50 \mathrm{~g} \mathrm{~L} \mathrm{~L}^{-1}$, and maintained under isothermal conditions of $20^{\circ} \mathrm{C} \pm 1{ }^{\circ} \mathrm{C}$ until uptake equilibrium was attained, confirmed by determination of mass variation. Prior to utilization, wood chips were collected and excess wine was removed with absorbent paper.

\subsection{Extraction methodology}

Extractions of compounds from wood were conducted in Pyrex tubes fitted with Teflon caps, with a wood/hydroalcoholic solution ratio of $20 \mathrm{~g} \mathrm{~L}^{-1}$, varying ethanol concentration and $\mathrm{pH}$ of the hydroalcoholic solutions as presented in Section 2.4. Contact was promoted in an incubator maintaining isothermal conditions and orbital agitation of $150 \mathrm{~min}^{-1}$ for $48 \mathrm{~h}$, determined in preliminary assays to be the sufficient time for extraction to stabilize for the least favorable conditions. At the end of the contact period, wood was separated from the hydroalcoholic solutions which were analyzed for total phenolic content and volatile composition.

\subsection{Experimental planning}

For a better understanding of variables effect on the extraction of chemical compounds from used wood, a 1 block -3 level Box-Behnken factorial design was outlined, with triplicates on the central point. Extractions were performed using hydroalcoholic solutions varying ethanol concentration, by volume, from $5 \%$ to $35 \%$, temperatures ranging from $30^{\circ} \mathrm{C}$ to $50^{\circ} \mathrm{C}$ and $\mathrm{pH}$ values ranging from 3 to 5 , covering the commonly found in spirits, wines and beer. Detailed information regarding outline and runs of the Box-Behnken experimental planning can be found in Supplementary Table 1. Factorial designs allowed the mathematical modeling of the extraction of each compound correlating with variable values according to Eq. (1):

$C_{x}=b+a_{1} \times \frac{C_{\mathrm{EtOH}}}{\%}+a_{2} \times\left(\frac{C_{\mathrm{EtOH}}}{\%}\right)^{2}+b_{1} \times \mathrm{pH}+b_{2} \times \mathrm{pH}^{2}+c_{1} \times\left(\frac{T}{{ }^{\circ} \mathrm{C}}\right)+c_{2} \times\left(\frac{T}{{ }^{\circ} \mathrm{C}}\right)^{2}$

where $C_{x}$ is the concentration of each compound, $b$ is the $y$-intercept, $a_{1}$, $b_{1}$ and $c_{1}$ are the linear and $a_{2}, b_{2}, c_{2}$ the quadratic coefficients for ethanol, $\mathrm{pH}$ and temperature respectively. $C_{\mathrm{EtOH}}$ is the concentration of ethanol in the hydroalcoholic solution, as percentage by volume, $\mathrm{pH}$ is the cologarithm of material concentration of $\mathrm{H}^{+}$ions in the hydroalcoholic solution and $T$ is the temperature of contact. After screening of the variables with impact on extraction of used wood chemical compounds, a replicate assay mimicking ethanol concentrations typically found in aged beverages (15\% - wine, $25 \%$ - fortified wine and liquors, $45 \%$ - spirits) was performed at $30^{\circ} \mathrm{C}$ and $50{ }^{\circ} \mathrm{C}$ using four replicates $(n=4)$ for proper statistical analysis. For a better comprehension of the work rationale, schematic representation of experimental work can be found in Supplementary Fig. 1.

\subsection{Analysis of total phenolic content}

Total phenolic content in the hydroalcoholic extracts was assessed by spectrophotometry using an adaptation of the method for tannin quantification (Mercurio, Dambergs, Herderich, \& Smith, 2007). A saturated ammonium sulfate solution was added to the hydroalcoholic extracts for protein precipitation and the supernatants absorbance was read at $280 \mathrm{~nm}$ using a Greiner UV-Star ${ }^{\circledR} 96$ well microplate to 
determine total phenolic content. Total phenolics were expressed as equivalents of $(-)$-epicatechin using a calibration curve prepared with pure (-)-epicatechin standards.

\subsection{Analysis of volatile compounds}

Volatile compounds in the hydroalcoholic extracts were analyzed by gas chromatography coupled with mass spectrometry (GC-MS), following the procedure proposed by Oliveira and collaborators (Oliveira, Faria, Sá, Barros, \& Araújo, 2006). Wood extract samples were diluted, when necessary, to achieve ethanol concentration below $15 \%$ for a final volume of $8 \mathrm{~mL}$, extracted with $400 \mu \mathrm{L}$ of dichloromethane (SupraSolv for gas chromatography, Merck), after adding 4-nonanol as internal standard $(3.2 \mu \mathrm{g})$. Extractions were performed in Pyrex tubes fitted with Teflon caps, with agitation promoted by a stir bar during $15 \mathrm{~min}$. Extracts were recovered with Pasteur pipette, dehydrated with anhydrous sodium sulfate and analyzed in a gas chromatograph Varian 3800 equipped with a 1079 injector and an ion-trap mass spectrometer Varian Saturn 2000. Each $1 \mu \mathrm{L}$ injection was made in splitless mode $(30 \mathrm{~s})$ in a Sapiens-Wax MS column $(30 \mathrm{~m} \times 0.15 \mathrm{~mm} ; 0.15 \mu \mathrm{m}$ film thickness, Teknokroma). Carrier gas was helium 49 (Praxair) at a constant flow of $1.3 \mathrm{~mL} \mathrm{~min}^{-1}$. The detector was set to electronic impact mode with an ionization energy of $70 \mathrm{eV}$, a mass acquisition range $(\mathrm{m} / \mathrm{z})$ from 35 to 260 and $610 \mathrm{~ms}$ acquisition interval. The oven temperature was initially set to $60^{\circ} \mathrm{C}$ for $2 \mathrm{~min}$ and then raised to $234^{\circ} \mathrm{C}$ at a rate of $3{ }^{\circ} \mathrm{Cmin}^{-1}$, raised again to $260^{\circ} \mathrm{C}$ at $5{ }^{\circ} \mathrm{C} \mathrm{min}{ }^{-1}$ and finally maintained at $260{ }^{\circ} \mathrm{C}$ for $10 \mathrm{~min}$. Injector temperature was set to $250^{\circ} \mathrm{C}$ with a $30 \mathrm{~mL} \mathrm{~min}^{-1}$ split flow and transfer line was maintained at $250^{\circ} \mathrm{C}$. Compounds were identified using MS Workstation version 6.9 (Varian) software, by comparing mass spectra and retention indices with those of pure standards and quantified as 4-nonanol equivalents.

\subsection{Statistical analysis}

Factorial designs and corresponding regressions for each response factor were performed in Statistica 7 software (Statsoft). Significant effects on the validation assay were evaluated by pairwise comparisons for each compound in the different studied conditions using a KruskallWallis analysis, without Dunn correction, performed in XLSTAT software (Addinsoft).

\section{Results and discussion}

Extraction of compounds from used woods was studied with the aim of understanding adsorption of wine volatile compounds by wood during the previous contact, and to demonstrate its potential and impact when reused for ageing other beverages. In a first step a factorial design was performed for a preliminary screening of the effect of variables in the extraction of wood and wine compounds. The extraction of each volatile compound was modeled individually according to Eq. (1), with the modeled coefficients presented in Table 1. As seen, good regression coefficients were obtained for the extraction of compounds from used American oak, with $R^{2}$ values ranging mostly from 0.8 up to 0.98 with the exception of 3-methyl-1-butanol, guaiacol and octanoic acid which presented $R^{2}$ between 0.6 and 0.8 . Extraction of compounds from French oak presented lower regression coefficients, mostly in the range of 0.7 to 0.9 . Despite the lower regression coefficients, models obtained for extraction of used French oak compounds are still satisfactory for describing most of the interactions and allow an evaluation of effects, as long as properly supported by the replicates assay also presented. Analyzing the models for compound extraction, it can be seen that esters (isoamyl acetate, ethyl hexanoate, ethyl lactate, diethyl succinate and diethyl malate) alcohols (2-phenylethanol and 3methyl-1-butanol) and acids (octanoic acid) were extracted from both used American and French oak. These compounds are not usually found in oak wood and their presence and extraction is a consequence of wood enrichment with fortified wine composition during the preceding contact as previously demonstrated (Coelho et al., 2019). Therefore, the previously established hypothesis that wood can be a vector for transferring and recombining volatile compounds from one matrix to another is confirmed. Analyzing the models and the observed effects, it can be seen that ethanol concentration in the hydroalcoholic solution had a significant effect on the overall extraction of volatile compounds from either American or French oak, being the most influent variable among the ones studied.

Ester extraction seemed to be favored by ethanol concentration as seen by $a_{1}$ and $a_{2}$ coefficients obtained for the models from used American oak and used French oak. Correlating the data obtained by the models with the observed in the assay mimicking ethanol concentration typically found in beverages presented in Figs. 3 and 4, a positive relation between ethanol concentration and extraction is visible for isoamyl acetate, diethyl succinate and ethyl hexanoate, being only statistically significant in the case of ethyl hexanoate. Ethyl hexanoate was the only ester whose extraction was affected by temperature, in the specific case of American oak, as seen by the $c_{1}$ coefficients obtained in the model. Nevertheless, such effect of temperature was not observed in the models for used French oak, neither it is statistically significant in the replicates assay for both oak woods. For ethyl lactate and diethyl malate, no trends were verified in the replicate assay, whereas for isoamyl acetate and diethyl succinate trends were noticeable but without statistical significance. These trends are justified by the response surfaces obtained from the models for each compound presented in Fig. 1. In fact, for ethyl lactate and diethyl malate, a significant effect of ethanol is found when increasing its content up to about $15 \%$, point from where the concentration of these compounds stabilizes, whereas for isoamyl acetate and diethyl succinate, this stabilization was not observed. Therefore, a weaker adsorption with wood can be indirectly observed for ethyl lactate and diethyl malate, which are easily extracted with lower ethanol concentrations, whereas isoamyl acetate and diethyl succinate extraction is improved with increasing ethanol concentration. Presenting a more efficient extraction with increasing ethanol concentration, ethyl hexanoate and ethyl octanoate demonstrate a stronger interaction with wood. Extraction of ethyl octanoate was clearly influenced by ethanol concentration, as demonstrated in the replicates assay, which is in good agreement with the behavior obtained for the remaining esters. Moreover, higher partition coefficients have been also reported for ethyl hexanoate and ethyl octanoate in wood sorption of volatiles from a model wine (Ramirez et al., 2001). Therefore, the stronger interactions and affinities observed and discussed in this work are in good agreement with the previously described by Ramirez and collaborators for these compounds, reinforcing the validity of the obtained results.

Thus, the hypothesis that interaction of esters with oak wood is of hydrophobic nature gains strength, since increasing ethanol concentration breaks the bond of esters with wood more efficiently. Ethanol is a low polar solvent compared to water which is strongly polar. Increasing ethanol concentration in ethanol-water solutions modifies the polarity of the solvent and allows the extraction of compounds of more hydrophobic nature by a "like dissolves like" principle (Zhang et al., 2007). Taking into account the values of XLogP3, a computational prediction of the $\log P$ value (Cheng et al., 2007) which indicates a molecule hydrophobicity (Barrera-García et al., 2008), presented in Table 2, a clear relation between XLogP3 values reported (National Center for Biotechnology Information, 2018) and the extraction profiles can be established. Diethyl malate and ethyl lactate, which were easily extracted in all the conditions of the validation assays, have low XLogP3 values. Diethyl succinate and isoamyl acetate, which demonstrate intermediate XlogP3 values, showed the effect of ethanol concentration on compound extraction but this was not statistically significant on the validation assay. Lastly, ethyl hexanoate and ethyl octanoate with the higher XLogP3 values showed significant effect of ethanol concentration on extraction either both in the models and the 


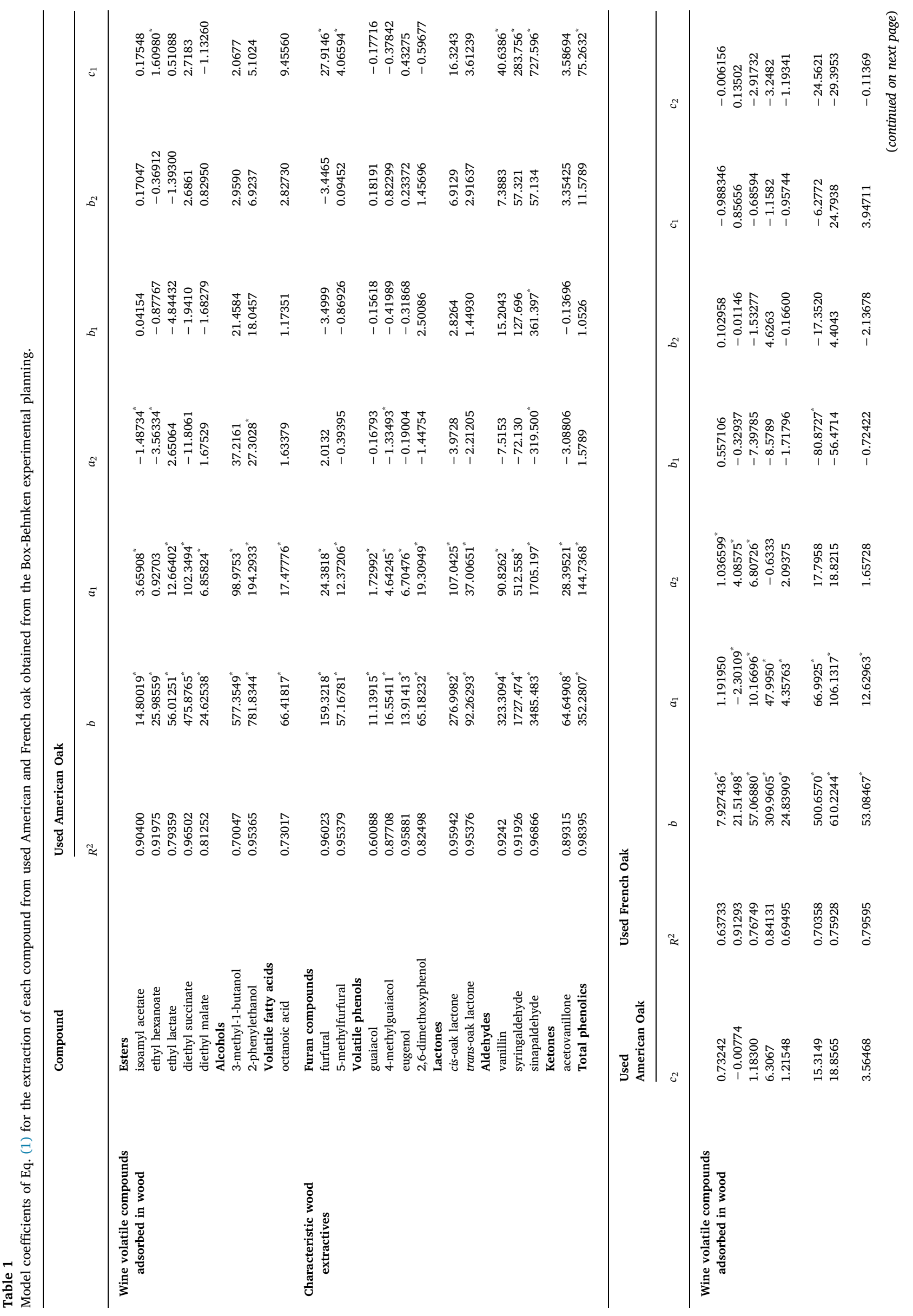


validation assay. The behaviors of 3-methyl-1-butanol and 2-phenylethanol were similar to the ones previously discussed for esters. Their extraction from used wood was mainly affected by ethanol concentration, with 2-phenylethanol and 3-methyl-1-butanol presenting stabilization of extraction around $20 \%$, by volume, according to the obtained models. Comparing this value with the replicates assay, the tendency predicted by the models are hinted but the deviations obtained hinder statistically significant differences, in similarity to the observed for isoamyl acetate and diethyl succinate. Lastly, octanoic acid extraction was also affected by increasing ethanol concentration. A slight effect of temperature was also observed but it was not considered significant neither by the models nor the replicates assay. A clear relation can be seen between the compounds XLogP3 values and their extraction behavior, demonstrating that interaction with wood is influenced by hydrophobicity of compounds. Previous works have suggested that acidbase and polar characteristics of wood were involved in the sorption mechanism (Ramirez et al., 2001). Overall pH effect was not considered significant in the extraction of wine volatiles from used oak wood, nor the extraction of typical wood extractives, with the exception of sinapaldehyde. Results demonstrate that $\mathrm{pH}$ changes in the range typically found in alcoholic beverages (from 3 to 5 ) did not affect binding of compounds to wood, putting again more emphasis on polarity of sorbent and sorbate. This finding is in good agreement with the demonstrated by the work of Barrera-García et al. (2008), which reported two types of interactions for the sorption of volatile phenols onto wood. Wood macromolecules were reported to be involved in sorption, with cellulose and hemicellulose retaining sorbate by non-specific hydrophilic interactions and lignin adsorbed volatile phenols by selective interactions of hydrophobic nature. Based on our results, sorption of wine volatiles is also of hydrophobic/hydrophilic nature, confirming Barrera-Garcia's observations (Barrera-García et al., 2008) and clarifying the hypothesis established by Ramirez's work (Ramirez et al., 2001). Focusing on typical wood extractives, several groups of compounds were extracted from used wood, namely volatile and non-volatile phenolic compounds, lactones, furan compounds and aldehydes, as visible in Table 1 and Figs. 2-4. These are in good agreement with the reported for wood (Wilkinson et al., 2013) and the previously reported for used woods produced in the same conditions (Coelho et al., 2019). These compounds were described as the main contributors to wood aroma in wines and spirits, and are easily extracted from wood by ethanol-water solutions taking into account their solubility and ethanolysis of lignin (Mosedale \& Puech, 1998). Models for extraction of phenolic compounds were outlined, with the corresponding coefficients presented in Table 1 and response surfaces in Fig. 2. Models obtained for both used American and French oak clearly demonstrate a positive effect of temperature and ethanol concentration on the overall extraction of phenolic compounds, as demonstrated by the response surfaces as well as by the coefficients presented in Table 1. Several works focusing on extraction of phenolic compounds from wood have also identified ethanol concentration and temperature as the main contributors for the recovery of these compounds (Ghitescu et al., 2015; Jung, Park, \& Yang, 2016), as well as the absence of influence of pH on the extraction of such compounds, as seen for ellagic tanins and ellagic acid (Jordão, Ricardo-da-Silva, \& Laureano, 2005). Thus, the obtained models are in good agreement with the described in the literature. Overall extraction of phenolic compounds was higher in used French oak when compared with used American oak. This was expected, taking into account the higher content of French oak in ellagitannins (Navarro et al., 2016) and phenolic acids, especially ellagic acid, in relation to the American variety (Garcia et al., 2012). Regarding the extraction of typical wood volatiles, several groups were extracted either from used French and American oak, but models for guaiacol, 4-methylguaiacol and eugenol are absent for used French oak due to difficulties in determining their concentrations in some runs of the factorial designs, with co-eluting peaks in the chromatograms. Nevertheless, such models were determined for used American oak, which demonstrate that 
a)

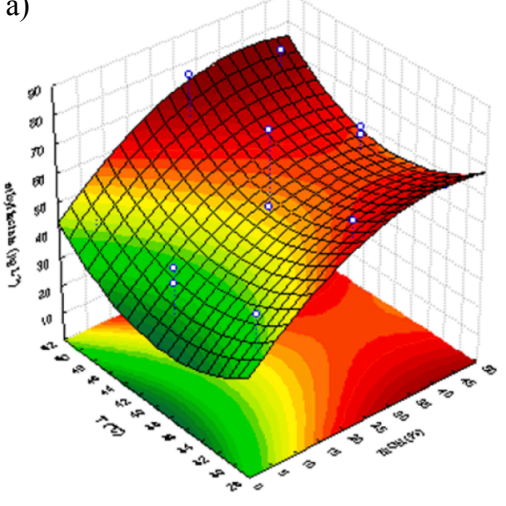

b)

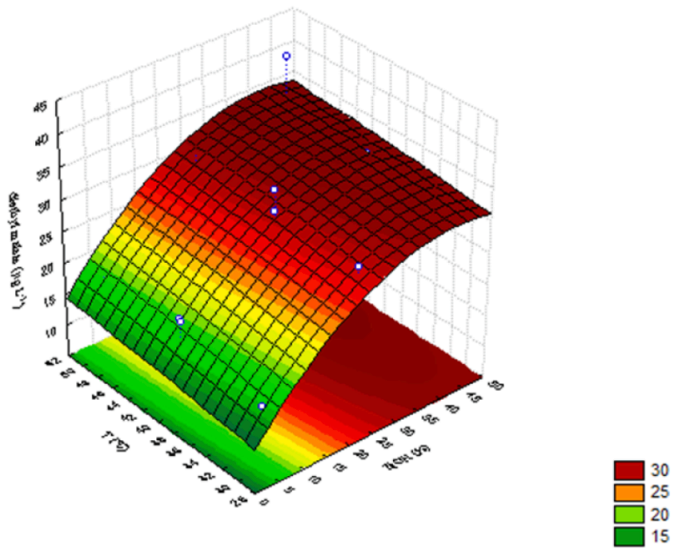

Fig. 1. Response surfaces correspondent to ester extraction models from used American oak for a) ethyl lactate and b) diethyl malate.

Table 2

Values of XlogP3 reported for wine volatiles adsorbed by wood (National Center for Biotechnology Information, 2018).

\begin{tabular}{llll}
\hline Compound & XLogP3 & Compound & XLogP3 \\
\hline diethyl malate & 0.1 & ethyl octanoate & 3.5 \\
ethyl lactate & 0.2 & 3-methyl-1-butanol & 1.2 \\
diethyl succinate & 1.2 & 2-phenylethanol & 1.4 \\
isoamyl acetate & 2.0 & octanoic acid & 3.0 \\
ethyl hexanoate & 2.4 & & \\
\hline
\end{tabular}

extraction of those compounds was mainly affected by ethanol concentration, being temperature and $\mathrm{pH}$ not considered significant factors. These results were confirmed by the replicates assay, where increased extraction with increasing ethanol concentration can be seen, with prominent significance for eugenol. Validation data obtained for used French oak is coherent with the observed for used American oak. Extraction of furan compounds demonstrated characteristic behavior when comparing used American oak with used French oak. Models for extraction of furfural and 5-methylfurfural showed a positive effect of ethanol concentration and temperature. This is also verified in the validation assay where a significant positive effect of temperature is observed, mainly for extractions conducted with lower ethanol percentages. A negative effect of ethanol is visible mainly in the extractions conducted at $50{ }^{\circ} \mathrm{C}$. However, in the case of French oak, effects were hindered by the poor quality of the model obtained for furfural as no significant effects could be observed. These were also not clear for 5methylfurfural in the validation assay, with no statistically significant tendencies observed. Lactones were only extracted from used American oak, while the staves of French oak had no detectable amounts of these compounds as demonstrated in previous works (Coelho et al., 2019). The obtained models demonstrate that only ethanol concentration affected significantly the extraction of those molecules, which was also verified in the validation assay. Lastly, another important group of compounds is aldehydes, with special focus on vanillin due to its characteristic aromatic properties. The effect of $\mathrm{pH}$ was only significant for sinapaldehyde extraction, as the extraction of aldehydes was mainly affected by ethanol and temperature, which is also clear in the validation assay.

On a broader analysis of the results, the different effects observed demonstrate that different volatile compositions can be attained reusing the same wood in subsequent beverages. As demonstrated, extraction of wine compounds adsorbed in wood (esters and alcohols) was only affected by ethanol concentration, and independent of temperature, whereas recovery of wood extractives (aldehydes and phenolic compounds) was generally affected both by ethanol concentration and by contact temperature. If a technological approach for application of
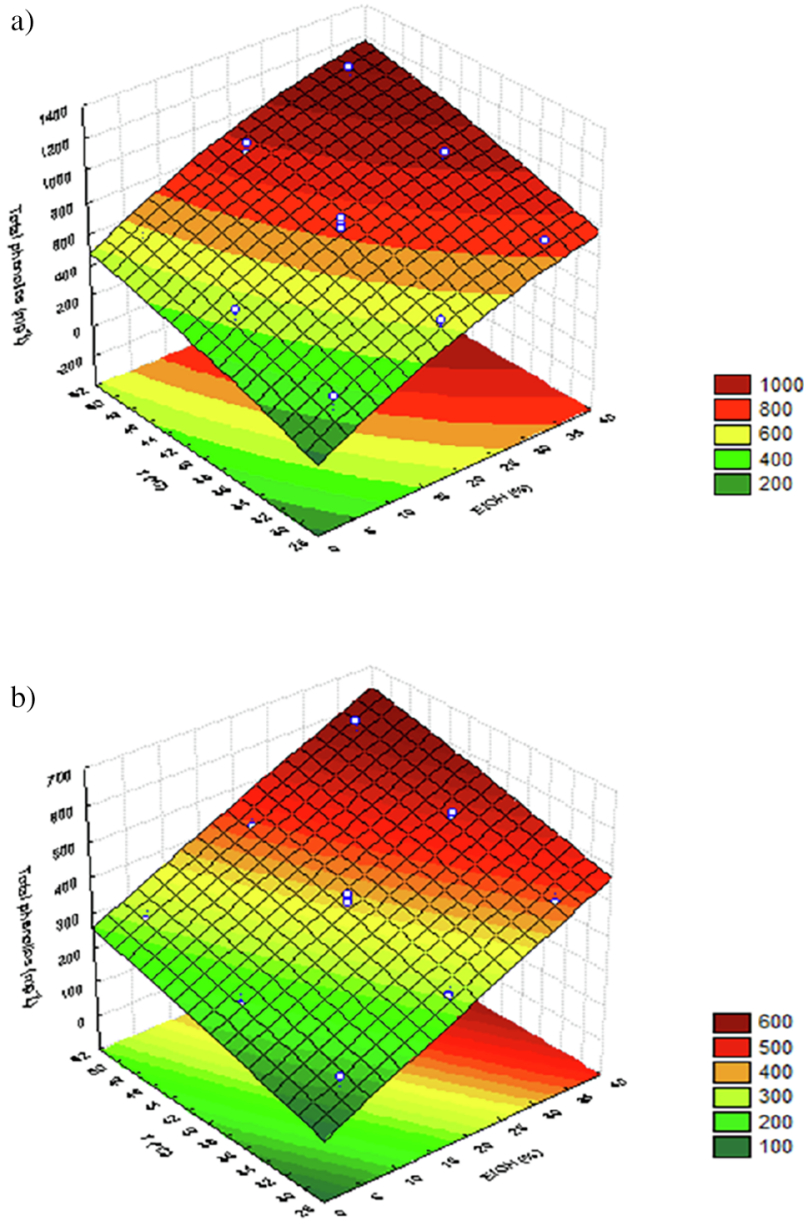

Fig. 2. Response surfaces for extraction of phenolic compounds from a) used French oak and b) used American oak.

wood in accelerated ageing processes is envisaged, different chemical and sensory profiles can be obtained manipulating temperature, ethanol concentration in the beverage or wood concentration and provenance. For instance, the use of low temperatures can favor the extraction of adsorbed wine volatiles, imparting the beverage mainly with esters. On the other hand, if higher temperatures are used, typical sensory characteristics associated to wood will be favored, as a consequence of a higher extraction of phenolic compounds and wood volatile compounds. Summing up, used wood can impact ageing beverages by transferring both compounds from the previous beverage and 

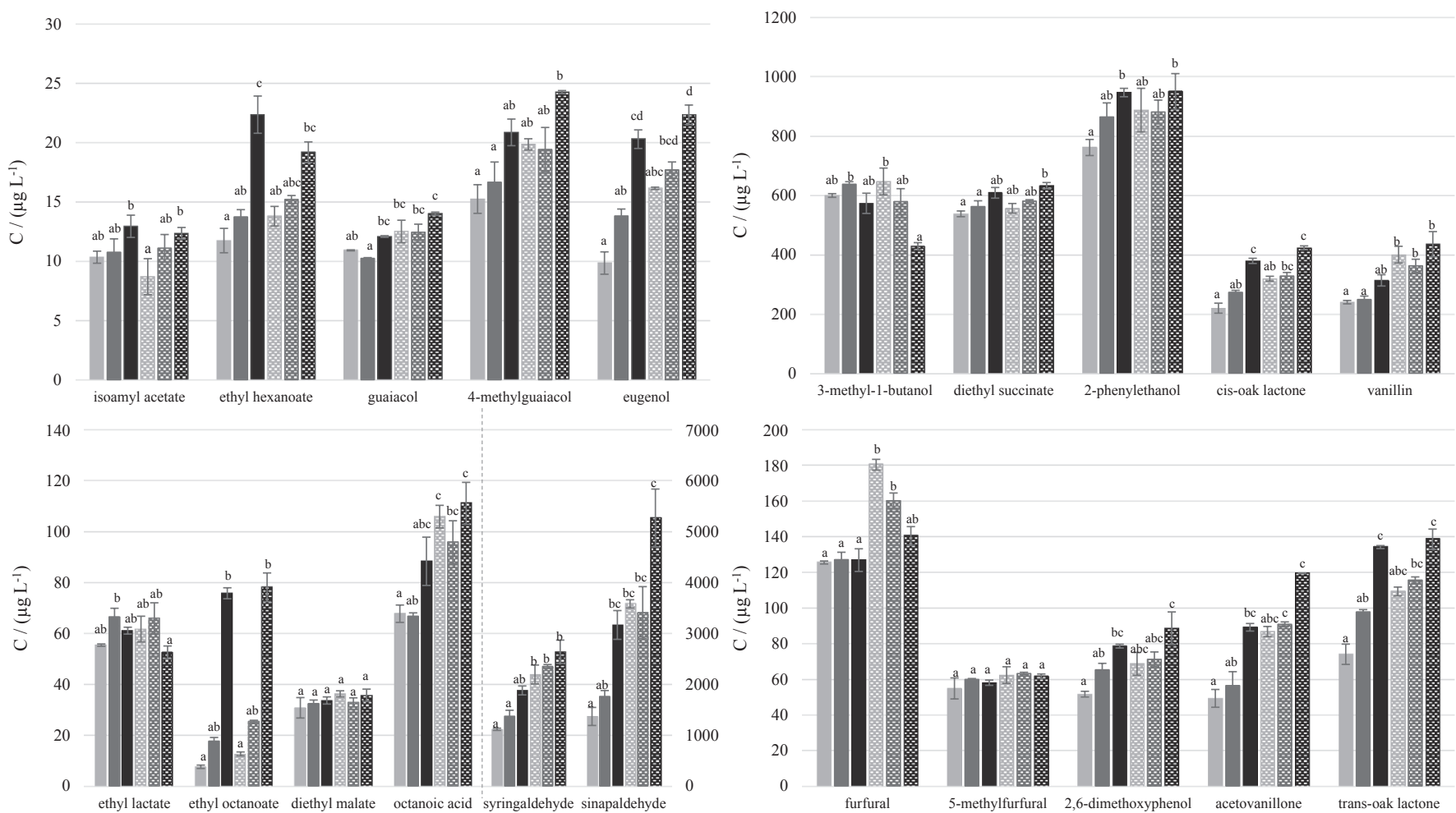

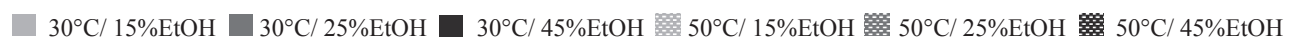

Fig. 3. Volatile compounds concentrations $(C)$ obtained for replicates extraction at different conditions from Used American Oak. Syringaldehyde and sinapaldehyde are found plotted on the secondary axis.
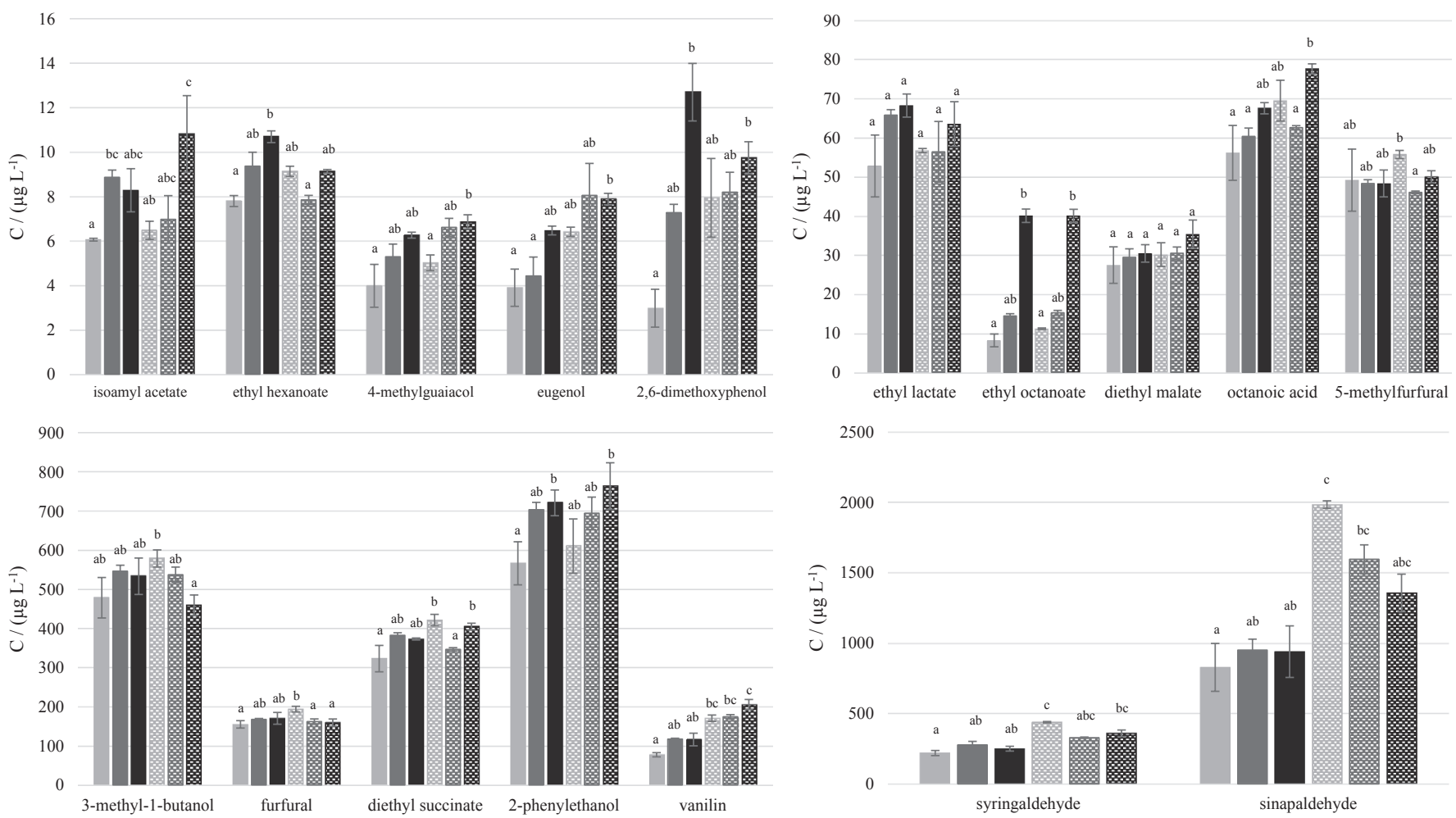

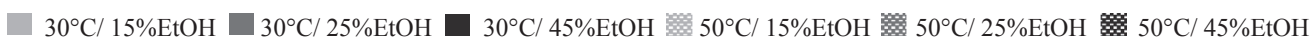

Fig. 4. Volatile compounds concentrations $(C)$ obtained for replicates extraction at different conditions from Used French Oak. 
from wood itself. Esters and alcohols migrating through wood can confer a fruity and floral flavor to aged beverages, along with characteristic wood aromas such as vanilla, coconut, and nuts. Profound knowledge of sorption and extraction processes occurring in wood converts it into an even more useful tool to be used as a transference vector in beverage ageing. Recombination of volatile compounds can be performed by controlling wood/beverage combinations and ageing conditions, on the basis of the obtained knowledge.

\section{Conclusions}

Ethanol concentration of a solution/beverage is the main variable affecting extraction of wine volatiles adsorbed in wood and characteristic wood extractives. Hence, the hypothesis that sorption of wine volatile compounds by wood is mainly due to polar or hydrophobic interactions is confirmed, being refuted or diminished the importance of acid base characteristics on this sorption phenomenon. Considering that hydrophobic characteristics are involved in sorption of wine volatiles by wood, the interaction established depends on both wood composition and volatile compounds intrinsic structure. Extraction of phenolic compounds is not only affected by ethanol concentration in the beverage but also by contact temperature, which is also verified for main wood extractives with the exception of volatile phenols. Also the second hypothesis is confirmed, when reused between ageing different beverages, wood transports sensory active compounds from one beverage to another, being the extraction of these compounds strongly dependent on beverage characteristics and contact conditions used.

\section{Declaration of Competing Interest}

None.

\section{Acknowledgments}

This work was supported by the Portuguese Foundation for Science and Technology (FCT) under the scope of the strategic funding of UID/ BIO/04469/2019 unit and COMPETE 2020 (POCI-01-0145-FEDER006684) and BioTecNorte operation (NORTE-01-0145-FEDER-000004) funded by the European Regional Development Fund under the scope of Norte 2020 - Programa Operacional Regional do Norte. Fermentum Engenharia das Fermentações Lda. also participated in co-funding this work. Authors also want to acknowledge Liliana Araújo for the helpful contribution and assistance in sample preparation. Lastly, authors would like to thank Mr. Benoit Verdier and Seguin Moreau for supplying the woods and Mr. Paulo Coutinho and Quinta do Portal for supplying the fortified wine.

\section{Appendix A. Supplementary data}

Supplementary data to this article can be found online at https:// doi.org/10.1016/j.foodchem.2019.05.093.

\section{References}

Barrera-García, V. D., Gougeon, R. D., Di Majo, D., De Aguirre, C., Voilley, A., \& Chassagne, D. (2007). Different sorption behaviors for wine polyphenols in contact with oak wood. Journal of Agricultural and Food Chemistry, 55(17), 7021-7027. https://doi.org/10.1021/jf070598v.

Barrera-García, V. D., Gougeon, R. D., Karbowiak, T., Voilley, A., \& Chassagne, D. (2008). Role of wood macromolecules on selective sorption of phenolic compounds by wood. Journal of Agricultural and Food Chemistry, 56(18), 8498-8506. https://doi.org/10. 1021/jf801314n.

Barrera-García, V. D., Gougeon, R. D., Voilley, A., \& Chassagne, D. (2006). Sorption behavior of volatile phenols at the oak wood/wine interface in a model system. Journal of Agricultural and Food Chemistry, 54(11), 3982-3989. https://doi.org/10.1021/ jf053043d.

Caldeira, I., Mateus, A. M., \& Belchior, A. P. (2006). Flavour and odour profile modifications during the first five years of Lourinhã brandy maturation on different wooden barrels. Analytica Chimica Acta, 563(1-2 SPEC. ISS.), 264-273. https://doi. org/10.1016/j.aca.2005.12.008

Cerdán, T. G., \& Ancín-Azpilicueta, C. (2006). Effect of oak barrel type on the volatile composition of wine: Storage time optimization. LWT - Food Science and Technology, 39(3), 199-205. https://doi.org/10.1016/J.LWT.2005.01.009.

Cheng, T., Zhao, Y., Li, X., Lin, F., Xu, Y., Zhang, X., ... Lai, L. (2007). Computation of octanol-water partition coefficients by guiding an additive model with knowledge. Journal of Chemical Information and Modeling, 47(6), 2140-2148. https://doi.org/10. 1021/ci700257y.

Chira, K., \& Teissedre, P. L. (2014). Chemical and sensory evaluation of wine matured in oak barrel: Effect of oak species involved and toasting process. European Food Research and Technology, 240(3), 533-547. https://doi.org/10.1007/s00217-0142352-3.

Coelho, E., Domingues, L., Teixeira, J. A., Oliveira, J. M., \& Tavares, T. (2019). Understanding wine sorption by oak wood: Modeling of wine uptake and characterization of volatile compounds retention. Food Research International, 116, 249-257. https://doi.org/10.1016/j.foodres.2018.08.025.

De Rosso, M., Cancian, D., Panighel, A., Dalla Vedova, A., \& Flamini, R. (2009). Chemical compounds released from five different woods used to make barrels for aging wines and spirits: Volatile compounds and polyphenols. Wood Science and Technology, 43(5-6), 375-385. https://doi.org/10.1007/s00226-008-0211-8.

Fernández de Simón, B., Cadahía, E., del Álamo, M., \& Nevares, I. (2010). Effect of size, seasoning and toasting in the volatile compounds in toasted oak wood and in a red wine treated with them. Analytica Chimica Acta, 660(1-2), 211-220. https://doi.org/ 10.1016/j.aca.2009.09.031.

Garcia, R., Soares, B., Dias, C. B., Freitas, A. M. C., \& Cabrita, M. J. (2012). Phenolic and furanic compounds of Portuguese chestnut and French, American and Portuguese oak wood chips. European Food Research and Technology, 235(3), 457-467. https://doi. org/10.1007/s00217-012-1771-2.

Ghitescu, R. E., Volf, I., Carausu, C., Bühlmann, A. M., Gilca, I. A., \& Popa, V. I. (2015) Optimization of ultrasound-assisted extraction of polyphenols from spruce wood bark. Ultrasonics Sonochemistry, 22, 535-541. https://doi.org/10.1016/j.ultsonch. 2014.07.013.

Gómez-Plaza, E., Pérez-Prieto, L. J., Fernández-Fernández, J. I., \& López-Roca, J. M. (2004). The effect of successive uses of oak barrels on the extraction of oak-related volatile compounds from wine. International Journal of Food Science and Technology, 39(10), 1069-1078. https://doi.org/10.1111/j.1365-2621.2004.00890.x.

González-Centeno, M. R., Chira, K., \& Teissedre, P. L. (2016). Ellagitannin content, volatile composition and sensory profile of wines from different countries matured in oak barrels subjected to different toasting methods. Food Chemistry, 210, 500-511. https://doi.org/10.1016/j.foodchem.2016.04.139.

Gonzalez, S. 2014. Bourbon Barrel Aging Optimization, 51(4), 106-109. http://doi.org/ 10.1094/TQ-51-4-1219-01.

Jordão, A. M., Ricardo-da-Silva, J. M., \& Laureano, O. (2005). Extraction of Some Ellagic Tannins and Ellagic Acid from Oak Wood Chips (Quercus pyrenaica L.) in Model Wine Solutions: Effect of Time, pH, Temperature and Alcoholic Content. South African Journal of Enology \& Viticulture, 26(2), 86-89. https://doi.org/10.21548/26-2-2122.

Jordão, A. M., Ricardo-Da-Silva, J. M., \& Laureano, O. (2007). Ellagitannins from Portuguese oak wood (Quercus pyrenaica Willd.) used in cooperage: Influence of geographical origin, coarseness of the grain and toasting level. Holzforschung, 61(2), 155-160. https://doi.org/10.1515/HF.2007.028.

Jung, J. Y., Park, H. M., \& Yang, J. K. (2016). Optimization of ethanol extraction of antioxidative phenolic compounds from torrefied oak wood (Quercus serrata) using response surface methodology. Wood Science and Technology, 50(5), 1037-1055. https://doi.org/10.1007/s00226-016-0846-9.

Lyons, T. P. (2014). North American whiskies: A story of evolution, experience, and an ongoing entrepreneurial spirit. Whisky, 39-48. https://doi.org/10.1016/B978-0-12401735-1.00005-2.

Mercurio, M. D., Dambergs, R. G., Herderich, M. J., \& Smith, P. A. (2007). High throughput analysis of red wine and grape phenolics - Adaptation and validation of methyl cellulose precipitable tannin assay and modified somers color assay to a rapid 96 well plate format. Journal of Agricultural and Food Chemistry, 55(12), 4651-4657. https://doi.org/10.1021/if063674n.

Mosedale, J. R., \& Puech, J. L. (1998). Wood maturation of distilled beverages. Trends in Food Science and Technology, 9(3), 95-101. https://doi.org/10.1016/S0924-2244(98) 00024-7.

National Center for Biotechnology Information (2018). PubChem Compound Database. Retrieved October 25, 2018, from https://pubchem.ncbi.nlm.nih.gov/.

Navarro, M., Kontoudakis, N., Gómez-Alonso, S., García-Romero, E., Canals, J. M., Hermosín-Gutíerrez, I., \& Zamora, F. (2016). Influence of the botanical origin and toasting level on the ellagitannin content of wines aged in new and used oak barrels. Food Research International, 87, 197-203. https://doi.org/10.1016/j.foodres.2016.07. 016.

Oliveira, J. M., Faria, M., Sá, F., Barros, F., \& Araújo, I. M. (2006). C6-alcohols as varietal markers for assessment of wine origin. Analytica Chimica Acta, 563(1-2), 300-309. https://doi.org/10.1016/J.ACA.2005.12.029.

Quinn, D. (2014). Irish whiskey. Whisky, 7-16. https://doi.org/10.1016/B978-0-12401735-1.00002-7.

Ramirez-Ramirez, G., Chassagne, D., Feuillat, M., Voilley, A., \& Charpentier, C. (2004). Effect of wine constituents on aroma compound sorption by oak wood in a model system. American Journal of Enology and Viticulture, 55(1), 22-26.

Ramirez, G. R., Lubbers, S., Charpentier, C., Feuillat, M., Voilley, A., \& Chassagne, D. (2001). Aroma compound sorption by oak wood in a model wine. Journal of Agricultural and Food Chemistry, 49(8), 3893-3897. https://doi.org/10.1021/ jf001334a.

Roullier-Gall, C., Signoret, J., Hemmler, D., Witting, M. A., Kanawati, B., Schäfer, B., ... Schmitt-Kopplin, P. (2018). Usage of FT-ICR-MS Metabolomics for Characterizing the 
Chemical Signatures of Barrel-Aged Whisky. Frontiers in Chemistry, 6(2), 1-11. https://doi.org/10.3389/fchem.2018.00029.

Spitaels, F., Wieme, A. D., Janssens, M., Aerts, M., Daniel, H. M., Van Landschoot, A., \& Vandamme, P. (2014). The microbial diversity of traditional spontaneously fermented lambic beer. PLoS One, 9(4), https://doi.org/10.1371/journal.pone.0095384.

Wilkinson, K., Li, S., Grbin, P., \& Warren, P. (2013). Barrel reclamation: Everything that's old can be new again. Australian and New Zealand Grapegrower and Winemaker, 594, $70-72$.
Zhang, B., Cai, J., Duan, C. Q., Reeves, M. J., \& He, F. (2015). A review of polyphenolics in oak woods. International Journal of Molecular Sciences, 16(4), 6978-7014. https://doi. org/10.3390/ijms16046978.

Zhang, Z. S., Li, D., Wang, L. J., Ozkan, N., Chen, X. D., Mao, Z. H., \& Yang, H. Z. (2007). Optimization of ethanol-water extraction of lignans from flaxseed. Separation and Purification Technology, 57(1), 17-24. https://doi.org/10.1016/j.seppur.2007.03. 006. 